V Congresso Brasileiro de Informática na Educação (CBIE 2016)

Anais dos Workshops do V Congresso Brasileiro de Informática na Educação (CBIE 2016)

\title{
Criação de games na escola: uma experiência de interação, programação e ludicidade
}

\author{
Vinicius C. de Aragão', Sandra C. M. de Souza Dias' ${ }^{1}$, Siddharta D. A. Fernandes² \\ ${ }^{1}$ Colégio Andrews - Rio de Janeiro - RJ - Brasil \\ ${ }^{2}$ Colégio Pedro II - Rio de Janeiro - RJ - Brasil \\ vinyaragao@hotmail.com, sancrisdias@yahoo.com.br, siddharta@superig.g12.br
}

\begin{abstract}
:
The main focus of this article is to present an experience on game development as a learning tool and reflect about pedagogical implications resulted from the game as a discipline approach. This experience took place at elementary school with seventeen students, from 7th grade, as they described the steps of creating an action game based on the program RPG Maker, providing a constructive, cooperative and meaningful learning.
\end{abstract}

\section{Resumo:}

Este artigo tem como foco principal apresentar uma experiência de desenvolvimento de games como ferramenta de aprendizagem. Realizada em uma instituição escolar, com um grupo de 17 alunos do $7^{\circ}$ ano do ensino fundamental, o estudo procurou descrever as etapas de criação de um jogo de ação, através do programa RPG Maker, resultando em uma aprendizagem construtiva, cooperativa e com significado para os alunos.

\section{Introdução}

Vivenciamos nos últimos anos grandes mudanças sociais. Sociedade em rede, Castells (1996), Cibercultura, Levy (2010) e Interatividade, Silva (2000) são alguns conceitos que emergiram com a evolução tecnológica. Todas essas mudanças exigem de nós uma nova postura social. Hoje, para estarmos inseridos nessa sociedade, é importante desenvolvermos cada vez mais a autonomia, autoria e virtualidade. Qualidades como a memorização de conteúdo, por exemplo, ficam ofuscadas frente à necessidade de compreender sentidos. Estabelecer nexos. Percebermos uma transformação importante na maneira como a comunicação, a cultura e a mídia se configuram na sociedade contemporânea.

E a Educação, como fica nesse cenário? Nóvoa (2009) enfatiza que: “É preciso abrir os sistemas de ensino a novas ideias. Em vez da homogeneidade e da rigidez, a diferença e a mudança”. Assim, um grande desafio da escola é proporcionar diferentes interfaces entre as linguagens contemporâneas, de forma que os jovens possam viver e interagir nesse mundo globalizado. Instruindo-os sob os aspectos tecnológicos, éticos, humanos e culturais, para que possam exercer sua cidadania de forma plena e busquem $o$ conhecimento com autonomia.

Para enfrentar esse desafio, propomos aos alunos do $7^{\circ}$ ano a criação jogos de ação. No cenário de imersão tecnológica em que vivemos, desenvolver um jogo de RPG - Sigla que em português significa "jogo de interpretação de personagens"- nos permitiu avaliar uma atividade pedagógica baseada em situações de identificação e interesse dos alunos.

Neste artigo pretendemos relatar a experiência vivenciada. Descrever as etapas de criação de um jogo de ação baseado no programa gratuito RPG Maker. Refletir sobre as 
V Congresso Brasileiro de Informática na Educação (CBIE 2016)

Anais dos Workshops do V Congresso Brasileiro de Informática na Educação (CBIE 2016)

implicações pedagógicas decorrentes do jogo como uma abordagem curricular. O trabalho que será apresentado se inspirou em autores que também promoveram iniciativas que abordam o desenvolvimento de games como ferramenta para aprendizagem, como por exemplo o trabalho produzido por Rodriguez, Zem-Lopes, Marques e Isotani (2015) que teve como objetivo desenvolver noções básicas do "pensamento computacional" com os alunos do primeiro ano do ensino médio de uma escola pública, através dos recursos do software "Scratch".

Esperamos acrescentar novos elementos na discussão do uso de jogos na aprendizagem. Contribuir com uma proposta pedagógica que alie a sedução e a magia dos jogos à uma aprendizagem consistente.

\section{Metodologia}

Jogo e Educação é uma relação antiga e com muitos casos de sucesso. Hoje, o avanço tecnológico permite a criação de jogos virtuais por alunos. "É uma atividade que, além da diversão, desenvolve a lógica de programação, a cooperação, a pesquisa e o protagonismo juvenil." Rodriguez, Zem-Lopes, Marques e Isotani (2015).

Para realizar essa atividade escolhemos o $7^{\circ}$ ano do Ensino Fundamental. Além de ser uma faixa etária que o jogo exerce um certo encanto, é um grupo de pré-adolescentes, com idades entre 12 e 13 anos, que fica na escola, no contra turno, realizando tarefas de estudo. Foram 20 encontros, às sextas-feiras, com duração de uma hora. As orientações para o desenvolvimento do trabalho foram realizadas em parceria entre o professor do Laboratório de Mídias e o de História.

O tema "Idade Média", foi escolhido por ter elementos históricos que se adequam bem a criação de um jogo de RPG. Após análise de alguns softwares, escolhemos o RPG Maker VX Ace. Essa ferramenta foi selecionada pois permite que o aluno crie os personagens e itens, e programe objetivos e conflitos de forma simples.

Cada dupla teve como objetivo criar uma história de jogo diferente, representando o modo de vida feudal, as suas principais classes sociais, a organização espacial, os conflitos da época, as descobertas, as invenções e as crises que a Europa passou nesse período. Inicialmente, oferecemos às equipes dois documentos baseados num GDD (Game Designer Document). Tabelas 1 e 2 . Esses documentos foram preenchidos por cada dupla de trabalho e serviram como um roteiro.

Quadro 1:

\begin{tabular}{|l|l|}
\hline Tema/ Título & Tema, dentro de "Idade Média". Ex: "Peste negra"/ Título \\
\hline Equipe & Dupla de trabalho \\
\hline Ambientação & Quando e onde se passa a história do jogo? O contexto. \\
\hline Roteiro & Enredo. \\
\hline Descrição & Breve descrição do protagonista e outros personagens. \\
\hline
\end{tabular}

Quadro 2: Storyboard

\begin{tabular}{|c|c|c|c|}
\hline Ordem & Cenário & Descrição & Programar \\
\hline 01 & $\begin{array}{c}\text { Ex: Casa } \\
\text { do herói }\end{array}$ & $\begin{array}{c}\text { Ex: Clicar na cama recupera "vida" do Herói. } \\
\text { A esposa diz para ir para o castelo do rei. }\end{array}$ & $\begin{array}{c}\text { Cama: + "vida". } \\
\text { Esposa e suas falas. }\end{array}$ \\
\hline
\end{tabular}


V Congresso Brasileiro de Informática na Educação (CBIE 2016)

Anais dos Workshops do V Congresso Brasileiro de Informática na Educação (CBIE 2016)

Segundo Flood apud Morais "O roteiro descreve, através do storyboard, o fluxo do jogo, ou seja, como o jogador irá alcançar o objetivo. ”(2015)

O cenário dos jogos representa o estilo de vida medieval, e para tanto, deveriam considerar os seguintes aspectos: desenvolvimento de um feudo, os laços de servidão camponesa, suserania e vassalagem, as ameaças estrangeiras, a igreja católica, o renascimento comercial e urbano e a crise do século XIV.

Os alunos trabalharam em duplas por acreditarmos que o confronto de ideias é enriquecedor para a construção do jogo. Consideramos que o exercício da negociação e o respeito a opiniões divergentes é saudável e necessário num momento de aprendizagem. Assim, diante de uma opinião conflituosa, o aluno pode se utilizar da argumentação para convencer o companheiro de equipe, que a sua ideia traz melhorias ao game. Esta postura cooperativa traz riqueza e heterogeneidade ao trabalho, desenvolvendo diversos elementos como: interação, colaboração, tomada de decisão em grupo, objetivos comuns, consciência social, inteligência coletiva e convivência com diferenças. Tais capacidades não dizem respeito apenas ao desenvolvimento do projeto em questão, mas também compõe qualidades pessoais imprescindíveis para o convívio social.

Dessa forma o exercício se dá não somente na habilidade de negociação do aluno, como também em sua capacidade de renúncia do que considerava ser o melhor para o jogo. Essas relações interpessoais no processo de aquisição do conhecimento têm um papel preponderante, como afirma Vygotsky (1998).

A mediação dos professores também foi fundamental. Além de orientar as pesquisas e a produção do roteiro, foi importante em momentos de reflexão sobre as diversas possibilidades de argumentação e de impasse. Na primeira fase do projeto, durante a criação do roteiro, as pesquisas ocorreram no sentido de entender a Idade Média e permitir o recorte de qual fase mais interessava aos alunos abordar na trama do jogo. Era nítida a curiosidade a respeito dos fatos que ocorreram, como por exemplo as guerras e as doenças. Ao se deparar com dúvidas mais específicas, recorriam à internet para a realização de pesquisas voltadas para o tema.

Concomitante a estes momentos de pesquisa e elaboração do storyboard, os alunos também puderam experimentar o programa e começar a criar. "É importante que logo nos primeiros passos se tenha a percepção de que o jogo já está sendo criado. Quando o estudante percebe que o jogo já se descortina, ele sente que é capaz de criá-lo. Este sentimento (...) se transforma em um estímulo interno onde o estudante sente que tem a competência de ir adiante e construir algo que não havia tentado antes. "Oliveira, Nogueira, Motta e Meirelles (2015).

Embora o jogo contasse com todo um trabalho de construção do mundo medieval, ele só tem significado se houver conflito, luta ou batalha. Segundo Crawford apud Giraffa "outra propriedade importante é o conflito. Não existe jogo sem este componente, mesmo quando não está ocorrendo uma competição entre dois usuários. " (2003) O game-over acontece no momento em que o herói perde alguma batalha e, no jogo, renasce a partir do momento em que salvou o game pela última vez, antes da derrota.

No momento, estamos em fase de finalização dos jogos. É muito interessante ver a realização dos alunos com o material que eles produziram. Além da realização, sentimos uma sensação de expectativa deles no sentido de como será a resposta dos seus colegas ao jogarem o game produzido por eles. Com certeza, a Idade Média ficará registrada para esses alunos de uma forma muito especial. 
V Congresso Brasileiro de Informática na Educação (CBIE 2016)

Anais dos Workshops do V Congresso Brasileiro de Informática na Educação (CBIE 2016)

\section{Resultados, discussão e conclusão}

Desenvolver jogos em um ambiente escolar foi uma atividade importante por diversos aspectos pedagógicos. O envolvimento dos alunos e a dedicação foram elementos evidenciados. Diariamente, no horário do recreio, diversos alunos passaram a frequentar o laboratório com o intuito de dar continuidade à confecção dos games. Foi notória uma onda motivacional, que os impulsionou para a realização de investigações fora do horário de estudo. Ao perceber que estes estímulos aconteceram de maneira espontânea, pôde-se avaliar que a proposta atingira um de seus objetivos principais, que era fazer com que os jovens buscassem o conhecimento com autonomia.

Percebemos, também, que a execução do projeto dividido em pesquisa, roteirização e programação facilitou a organização mental dos alunos. Fato que tornou a proposta totalmente adequada à faixa etária. Podemos destacar a facilidade que tiveram em programar eventos e criar conexões lógicas baseadas em pensamentos complexos. Tudo isso sem se dar conta de que estavam em uma "aula" sobre Idade Média.

O trabalho cooperativo foi a base das relações estabelecidas. Algumas duplas conseguiram se revezar com facilidade, entretanto outras precisaram de ajuda neste sentido. Foi necessário a intervenção em situações em que apenas um integrante programava. Surgiram conflitos, mas todos relacionados ao embate de opiniões e a criação dos jogos. Natural em um ambiente de construção.

Os jogos serão apresentados à comunidade escolar e às famílias durante a mostra pedagógica, no final deste ano. Sabendo dos prazos, os alunos demostraram comprometimento, que resultou em jogos com diálogos bem elaborados, seguindo uma continuidade e com um enredo condizente ao modo de vida da época.

Não existem regras para desenvolver a melhor maneira de incentivar e promover a aprendizagem. Esta é, dentre muitas outras, uma forma de atingir o interesse dos alunos. $\mathrm{O}$ que não deve ser tomado como uma prática única. Aliado a ela, as aulas de história também irão complementar sua função na construção do conhecimento. Como educadores, devemos lembrar que a infância e a adolescência são fases da vida onde a imaginação tem um grande papel na formação do indivíduo e sua importância deve ser levada a sério.

\section{Referências}

Bittencourt, J., Giraffa, L. (2003). A utilização dos Role-Playing Games Digitais no processo de Ensino-Aprendizagem. Technical Reports Series, n. 031, setembro

Rodriguez,C., Zem-Lopes,A., Marques,L., Isotani,S. (2015) Pensamento Computacional: transformando ideias em jogos digitais usando o Scratch. XXI Workshopde Informática na Escola (WIE 2015).

Oliveira, C., Nogueira,E., Motta,C., Meireles, L. (2015) Educação baseada na consrução de jogos. XXVI Simpósio Brasileiro de Informática na Educação - SBIE 2015

Morais,D., Gomes,T., Souza, A., Peres,F. Storyboards no desenvolvimento de jogos digitais educacionais por usuários finais:Um relato de Experiência. ( 2015) XXVI Simpósio Brasileiro de Informática na Educação - SBIE 2015

Vigotsky, L. S.; COLE, M. A formação social da mente: o desenvolvimento dos processos psicológicos superiores. 6. ed. São Paulo: Martins Fontes, 1998.

Nóvoa, António. Professores. Imagens do futuro presente. Lisboa: Educa, 2009.

Castells, Manuel (1996). A sociedade em rede. Volume 1. ed. Paz e Terra

Levy, P. (2010). Cibercultura. São Paulo: ed.34 